\title{
Informe Legal No. 01 - 2017 - Corte Constitucional
}

Legal Inform No. 01 - 2017 - Constitutional Court

Valeria Monserrath Sánchez Morales

Investigadora Jurídica, Estudio Jurídico Cevallos \& Noboa

Documento Original (Informe divulgativo) ${ }^{355}$

RFJ, No. 3, 2018, pp. 369-384, ISSN 2588-0837

PARA: Dr. Íñigo Salvador Crespo, Jur. PUCE

Decano de la Facultad de Jurisprudencia de la PUCE.

DE:

VALERIA MONSERRATH SÁNCHEZ MORALES

Investigadora Jurídica PUCE.

ASUNTO: SENTENCIA INTERPRETATIVA: 002-08-SI-CC

FECHA: Quito, enero 5 del 2018

Me dirijo a usted a fin de expresarle un cordial saludo y al mismo tiempo, para informarle, en atención al asunto y documentos de la referencia, lo siguiente:

\section{RESUMEN}

El presente informe tiene como base la Sentencia Interpretativa 002-08-SI-CC, donde el Consejo Nacional Electoral solicita a la Corte Constitucional la interpretación de las normas constitucionales relacionadas con el Consejo de Participación Ciudadana y Control Social, los métodos para escoger a los consejeros, y las personas responsables de esta labor. A partir de dicha problemática, la Corte Constitucional presenta las interrogativas de la solicitud de interpretación, las normas constitucionales que serán interpretadas, y menciona cuáles son las facultades de la Corte Constitucional en mate-

355 El presente documento fue sometido a revisión de pares externos 
ria de derecho, de entre las que presenta a la interpretación como la máxima competencia, conceptualiza dicho término y posteriormente inicia con el análisis hermenéutico.

Con respecto al informe personal, se ha realizado un análisis FODA, donde se presentan los factores visibles en la sentencia, y cómo estos han podido intervenir en la misma. Además de ello, se ha desarrollado un modelo de principal - agente, en donde se mencionan los organismos que intervienen y la relación que estos tienen con los puntos de interpretación que la sentencia presenta.

PALABRAS CLAVES: principal-agente, atribuciones, vinculación, jurisprudencia, vigencia.

ABSTRACT: This report is based on Interpretative Judgment 002-08-SI-CC, where the National Electoral Council requests the Constitutional Court to interpret the constitutional rules related to the Council for Citizen Participation and Social Control, the methods to choose the counselors, and the people responsible for this work. Departing from this legal scenario, the Constitutional Court presents the interrogatives of the request for interpretation, the constitucional rules to be analized, etc. I addition, a SWOT analysis has been carried out, where the factors visible in the judgment are presented, and how they have been able to intervene in it. Finally, a model of principal - agent has been developed, in which the agencies that intervene are mentioned and the relationship they have with the points of interpretation that the sentence presents.

KEYWORDS: principal-agent, attributions, linkage, jurisprudence, validity.

\section{ANTECEDENTES}

a. El 12 de diciembre de 2017 se recibe la Sentencia Interpretativa 002-08-SI-CC de los casos acumulados: 0005-08-IC y 0009-08IC, mediante la cual se solicita, por parte del Consejo Nacional Electoral, la interpretación del artículo 207 de la Constitución de la República del Ecuador, además de la Disposición Transitoria Segunda y de los artículos 1, 16, 17, y 29 del Régimen de Transición; a la Corte Constitucional. 
b. En la Sentencia Interpretativa 002-08-SI-CC se concluyó que la Comisión de Legislación y Fiscalización debe continuar con el proceso de designación de consejeros del Consejo de Participación Ciudadana y Control Social, y que dicha Comisión posee un período de 30 días para concluir con el proceso del concurso de oposición y méritos y designar a los consejeros.

c. La Sentencia Interpretativa otorgada constituye jurisprudencia obligatoria y vinculante.

d. El presente informe se redacta a partir de la solicitud del Dr. Rubén Méndez, de la opinión favorable a dicha sentencia, conforme a la legislación ecuatoriana vigente en la fecha de ejecución del mencionado documento legal.

\section{MARCO NORMATIVO}

A continuación, se resumen las principales disposiciones, sobre la base de las cuales se emite la opinión contenida en el presente informe:

\section{Constitución de la República del Ecuador 2008}

En el artículo 207 de la Constitución se menciona que el Consejo de Participación Ciudadana y Control Social está compuesto por siete consejeros principales y siete suplentes; cuya selección se realizará de los postulantes que sean propuestos por las organizaciones sociales y por la ciudadanía. El Consejo Nacional Electoral será el ente encargado de organizar el proceso de selección, y conducirá el concurso público de oposición y méritos (Asamblea Constituyente, 2008).

Por otro lado, en el artículo 429 de la Constitución, se aclara que la Corte Constitucional es el "máximo órgano de control, interpretación constitucional y de administración de justicia" (Asamblea Constituyente, 2008).

El artículo 436 de la Constitución establece, entre las atribuciones de la Corte Constitucional, las siguientes:

- Ser la máxima instancia de interpretación de la Constitución, de los tratados internacionales de derechos humanos ratificados por el Estado ecuatoriano, a través de sus dictámenes y sus decisiones. 
Sus sentencias tendrán carácter vinculante.

- Conocer y resolver las acciones públicas de inconstitucionalidad, por el fondo o por la forma, contra actos normativos de carácter general emitidos por órganos y autoridades del Estado.

- Expedir sentencias que constituyan jurisprudencia vinculante respecto de las acciones de protección, cumplimiento, hábeas corpus, hábeas data, acceso a la información pública y demás procesos constitucionales, así como los casos seleccionados por la Corte para su revisión.

La Disposición Transitoria Segunda de la Constitución, dispone que tras treinta días de entrar en vigencia la Constitución, el órgano legislativo designará con base en un concurso público de oposición y méritos a las consejeras y consejeros del primer Consejo de Participación Ciudadana y Control Social, que permanecerán provisionalmente en sus funciones hasta la aprobación de la ley correspondiente.

La Disposición Transitoria Tercera de la Constitución, establece que los miembros de la Comisión de Control Cívico de la Corrupción y de la Secretaria Nacional Anticorrupción, que no sean de libre nombramiento y remoción, pasarán a ser parte del Consejo de Participación Ciudadana y Control Social. A la vez menciona que las superintendencias funcionarán hasta que el órgano legislativo expida leyes correspondientes.

\section{Régimen de Transición}

En el artículo 1 del Régimen de Transición se menciona que los servidores de la Comisión de Control Cívico de la Corrupción y de la Secretaria Nacional Anticorrupción, serán parte del Consejo de Participación Ciudadana y Control Social. Las superintendencias seguirán en funcionamiento hasta que el legislativo expida las leyes correspondientes.

El artículo 17 del Régimen de Transición establece que los diputados y diputadas elegidos en el 2006 concluyen su período de funciones al entrar en vigencia la Constitución, para así transferir a la Comisión Legislativa y de Fiscalización las funciones de la Asamblea Nacional, hasta que se elijan y posesionen los Asambleístas definitivos.

En el artículo 29 del Régimen de Transición se menciona que la Comisión Legislativa, luego de 15 días desde su conformación, iniciará 
un concurso de oposición y méritos para la designación de los miembros del Consejo de Participación Ciudadana y Control Social. Las comisiones serán convocadas luego de la posesión de los dignatarios de elección popular mencionados en el Régimen de Transición.

\section{Ley Orgánica de Garantías Jurisdiccionales y Control Constitucinal (LOGJCC)}

El artículo 2 de la LOGJCC aclara los principios de interpretación de la ley, entre los que se menciona:

- Principio de aplicación más favorable a los derechos: si hay varias normas aplicables a un caso concreto, se debe elegir aquella que más proteja a los derechos de la persona.

- Optimización de los principios constitucionales: la creación, interpretación y aplicación del derecho deberá orientarse hacia el cumplimiento y optimización de los principios constitucionales.

- Obligatoriedad del precedente constitucional: los parámetros interpretativos de la Constitución fijados por la Corte Constitucional en los casos sometidos a su conocimiento tienen fuerza vinculante. La Corte podrá alejarse de sus precedentes de forma explícita y argumentada para garantizar la progresividad de los derechos y la vigencia del estado constitucional de derechos y justicia.

- Obligatoriedad de administrar justicia constitucional. No se puede suspender ni denegar la administración de justicia por contradicciones entre normas, oscuridad o falta de norma jurídica.

El artículo 3 de la LOGJCC establece que la interpretación constitucional se dará en el sentido que más se ajuste a la Constitución en su integralidad, y en caso de existir dudas, en el sentido que más favorezca a la plena vigencia de los derechos reconocidos en la Constitución. La interpretación se debe basar en:

- Reglas de solución de antinomias: entre varias normas, prevalece aquella que emana del órgano competente para regular la materia, después la jerárquicamente superior, después la especial y finalmente la posterior. 
- Principio de proporcionalidad: se verificará que la medida proteja un fin constitucional, que sea necesario garantizar, con protección y restricción.

- Ponderación: relación de preferencia entre los principios y normas, condicionada a las circunstancias del caso concreto.

- Interpretación evolutiva o dinámica: temporalidad.

- Interpretación sistemática: las normas deben ser interpretadas a partir del contexto general del texto normativo.

- Interpretación teleológica: las normas se interpretan según lo que persigue el texto normativo.

- Interpretación lineal: cuando la norma es clara, se entenderá a su tenor literal.

El artículo 154 de la LOGJCC establece que la Corte Constitucional, a petición de parte, realizará la interpretación de las normas de la parte orgánica de la Constitución, para establecer el alcance de dichas normas. Además, la Asamblea Nacional podrá expedir leyes sobre la materia que fue objeto de dictámenes interpretativos.

El artículo 155 de la LOGJCC establece quiénes podrán solicitar dictámenes de interpretación constitucional:

- El Presidente de la República.

- La Asamblea Nacional, por acuerdo del Pleno.

- La Función de Transparencia y Control Social, a través de su órgano rector.

- La Función Electoral, a través de su órgano rector.

- Cualquier persona que demuestre un respaldo del cero punto veinticinco por ciento del registro electoral nacional.

El artículo 158 de la LOGJCC establece que el dictamen interpretativo fijará el alcance de la norma constitucional objeto de la inter- 
pretación, a partir de los argumentos constitucionales y métodos que sirvan para fundamentarlo.

El artículo 170 de la LOGJCC establece que la Corte Constitucional es el máximo órgano de control e interpretación constitucional y del sistema de administración de justicia constitucional, siendo un órgano autónomo e independiente de los demás órganos del poder público, con jurisdicción nacional.

\section{Ley Orgánica del Consejo de Participación Ciudadana y Control Social (LOCPCCS)}

El artículo 22 de la LOCPCCS establece que el Consejo Nacional Electoral organizará el concurso público de oposición y méritos para la designación de consejeros del Consejo de Participación Ciudadana y Control Social. Para tal efecto se convocará en los idiomas oficiales de relación intercultural, en cadena nacional de radio y televisión, en la página web de la institución y en al menos tres diarios de circulación nacional.

\section{Código Civil ecuatoriano}

El Código Civil ecuatoriano, en el artículo 18, establece los métodos de interpretación de la norma. En él se dispone que se debe entender el espíritu de la ley, y que las palabras se entenderán en su sentido natural y obvio.

Ley Orgánica Electoral, Código de la Democracia

En el artículo 25 de la Ley Orgánica Electoral, Código de la Democracia, se establecen las funciones del Consejo Nacional Electoral, donde se mencionan las siguientes:

- Organizar, dirigir, vigilar y garantizar de manera transparente y eficaz los procesos electorales, convocar a elecciones, realizar los cómputos electorales, proclamar los resultados y posesionar a quienes resulten electos.

- Organizar y conducir el concurso público de oposición y méritos con postulación, veeduría y derecho a impugnación ciudadana para seleccionar a los consejeros del Consejo de Participación Ciudadana y Control Social, de conformidad con la ley. 
- Designar a los delegados de la Función Electoral ante las comisiones ciudadanas de selección organizadas por el Consejo de Participación Ciudadana y Control Social.

- Promover la formación cívica y democrática de los ciudadanos al incorporar el principio de interculturalidad.

\section{CONCEPTOS}

- Interpretación constitucional: "a interpretación de las normas jurídicas implica otorgarles un sentido" Rudzinsky, 2014); por lo tanto, se debe buscar el espíritu de la noma y el objetivo del legislador al redactar la ley, para así lograr adecuar la redacción de la norma al día a día de la sociedad. Al hacer referencia a la Interpretación Constitucional, se habla de la "convivencia política de un país, y la vigencia de las demás normas” (Rudzinsky, 2014).

- Sentencia Interpretativa: es un documento legal en el que "un juez con competencia, define y da sentido a una norma" (Porras \& Romero, 2006); lo que indica que un juez con competencia puede interpretar una norma en su materia, con el objetivo de brindar una justificación y rectificación al automatismo de la norma.

\section{Objetivo}

El objetivo del presente informe es analizar la SENTENCIA INTERPRETATIVA 002-08-SI-CC de los casos acumulados 0005-08-IC y 0009-08-IC; y proponer al Dr. Rubén Méndez la opinión solicitada en el numeral I, inciso d, según el marco normativo expuesto en el numeral II precedente. 


\section{ANÁLISIS}

a. Evaluación de la documentación

Se ha elaborado el presente informe en base al pedido de opinión favorable a la Sentencia Interpretativa 002-08-SI-CC, conforme a lo establecido en la legislación ecuatoriana, según el pedido recibido el 12 de diciembre del 2017.

b. Análisis FODA de la Sentencia Interpretativa 002-08-SI-CC 


\begin{tabular}{|c|c|}
\hline Fortalezas & Debilidades \\
\hline $\begin{array}{l}\text {-La Sentencia fue analizada y aproba- } \\
\text { da por cinco jueces, lo que permite } \\
\text { afirmar que la interpretación otor- } \\
\text { gada es adecuada y goza de consenso } \\
\text { jurídico con respecto al pedido reali- } \\
\text { zado. } \\
\text {-Se consideran todas las normas re- } \\
\text { lacionadas con el Régimen de Tran- } \\
\text { sición y con el Consejo de Participa- } \\
\text { ción Ciudadana y Control Social. } \\
\text {-La interpretación se facilita porque } \\
\text { el Consejo Nacional Electoral pre- } \\
\text { senta las interrogantes que necesitan } \\
\text { interpretación. } \\
\text {-Cada norma expresa de alguna ma- } \\
\text { nera el proceso a realizar para elegir } \\
\text { a los consejeros del Consejo de Parti- } \\
\text { cipación Ciudadana y Control Social. }\end{array}$ & $\begin{array}{l}\text {-Al ser elaborada en un período de } \\
\text { cambio de Constitución, se presentan } \\
\text { lagunas jurídicas en las que la aplica- } \\
\text { ción de la norma puede ser confusa. } \\
\text {-La sentencia interpretativa puede } \\
\text { ser imparcial, puesto que de alguna } \\
\text { manera podría reflejar las necesida- } \\
\text { des y deseos personales de los jueces } \\
\text { en este caso. } \\
\text {-Escaso tratamiento de los concep- } \\
\text { tos de Supremacía Constitucional, } \\
\text { eficacia directa, naturaleza jurídica, } \\
\text { eficacia normativa y reserva de ley, } \\
\text { además de las facultades de los orga- } \\
\text { nismos que intervienen. } \\
\text {-Conflictos de jerarquía entre la } \\
\text { Constitución y el Régimen de Tran- } \\
\text { sición. } \\
\text {-Vacíos legales impiden decidir de } \\
\text { manera clara qué responsabilidad tie- } \\
\text { ne la Comisión Legislativa y de Fisca- } \\
\text { lización con relación a la formación } \\
\text { del Consejo de Participación Ciuda- } \\
\text { dana y Control Social. }\end{array}$ \\
\hline Oportunidades & Amenazas \\
\hline $\begin{array}{l}\text {-Permite comprender de manera cla- } \\
\text { ra lo que la Constitución del } 2008 \\
\text { establece sobre las atribuciones de } \\
\text { la Función Legislativa, convirtiéndo- } \\
\text { se en un documento de ayuda para } \\
\text { próximos análisis e interpretaciones. } \\
\text { - Aporta un análisis profundo de la } \\
\text { posición doctrinal de juristas y trata- } \\
\text { distas de relevancia sobre el tema de } \\
\text { la interpretación. }\end{array}$ & $\begin{array}{l}\text {-Es necesario tratar con cuidado el } \\
\text { concepto de interpretación, procu- } \\
\text { rando que los recursos empleados } \\
\text { para ello sean los adecuados. } \\
\text {-Al ser el Ecuador un Estado consti- } \\
\text { tucional de derechos y justicia, se ve } \\
\text { influenciado de manera directa por el } \\
\text { entorno de desarrollo y el nivel de de- } \\
\text { mocracia existente; por lo que resulta } \\
\text { necesario analizar estos puntos en la } \\
\text { interpretación para definir la aplica- } \\
\text { ción que se debe dar a la norma. }\end{array}$ \\
\hline
\end{tabular}




\section{c. Modelo de Principal - Agente basado en la Sentencia 002-08-SI-CC}

Al ser el principal el sujeto de derechos, y el agente el medio de realización y ejecución de dichos derechos, se hace necesario visualizar los elementos y organismos que se abordan en la Sentencia Interpretativa. Estos últimos son:

- Consejo Nacional Electoral

- Corte Constitucional

- Consejo de Participación Ciudadana y Control Social

- Comisión Legisladora y de Fiscalización

De entre estos se deberá señalar que la Corte Constitucional es el agente del Consejo Nacional Electoral, ya que este es quien pide la interpretación de los artículos necesarios para el desarrollo del proceso de elección y fijación de los consejeros del Consejo de Participación Ciudadana.

Por otro lado, se puede considerar que el Consejo Nacional Electoral es el agente de la Comisión Legisladora y de Fiscalización, ya que el Consejo debe cumplir las órdenes de la Comisión con respecto al llamado al concurso de méritos y oposición, que es el tema de discusión de este caso.

\section{d. Determinación del organismo de interpretación}

En el artículo 429 de la Constitución se declara que la Corte Constitucional es el "máximo órgano de control, interpretación constitucional y de administración de justicia”, por lo que resulta ser la Corte Constitucional el intérprete válido de la Constitución del 2008. En el marco de su jurisdicción, la interpretación que la misma realiza es la veraz y la ejecutoria. 


\section{OPINIÓN FAVORABLE U OBSERVACIONES}

Tras analizar la Sentencia y la legislación ecuatoriana, y considerando el principio de supremacía constitucional, se propone emitir una opinión favorable a la Sentencia Interpretativa 002-08-SI-CC de los casos acumulados 0005-08-IC y 0009-08-IC.

A su vez, se resalta la importancia de que la Sentencia cuenta con la aprobación con cinco votos a favor, por lo que resulta evidente que la interpretación de los artículos pedidos está ejecutada con relación al espíritu de la ley y va de la mano de los principios constitucionales.

\section{RECOMENDACIONES}

Se recomienda analizar el concepto de la interpretación tomando como referencia lo mencionado en el artículo 18 del Código Civil ecuatoriano:

Los jueces no pueden suspender ni denegar la administración de justicia por oscuridad o falta de ley. En tales casos juzgarán en atención de las siguientes reglas:

1a. Cuando el sentido de la ley es claro, no se desatenderá su tenor literal, a pretexto de consultar su espíritu. Pero bien se puede, para interpretar una expresión oscura de la ley, recurrir a su intención o espíritu claramente manifestados en ella misma, o en la historia fidedigna de su establecimiento;

2a. Las palabras de la ley se entenderán en su sentido natural y obvio, según el uso general de las mismas palabras; pero cuando el legislador las haya definido expresamente para ciertas materias, se les dará en estas su significado legal;

3a. Las palabras técnicas de toda ciencia o arte se tomarán en el sentido que les den los que profesan la misma ciencia o arte, a menos que aparezca claramente que se han tomado en sentido diverso;

4a. El contexto de la ley servirá para ilustrar el sentido de cada una de sus partes, de manera que haya entre todas ellas la debida correspondencia y armonía. Los pasajes oscuros de una ley pueden ser ilustrados por medio de otras leyes, particularmente si versan sobre el mismo asunto; 
5a. Lo favorable u odioso de una disposición no se tomará en cuenta para ampliar o restringir su interpretación. La extensión que deba darse a toda ley se determinará por su genuino sentido y según las reglas de interpretación precedentes;

6a. En los casos a que no pudieren aplicarse las reglas de interpretación precedentes, se interpretarán los pasajes oscuros o contradictorios del modo que más conforme parezca al espíritu general de la legislación y a la equidad natural; $\mathrm{y}$,

7a. A falta de ley, se aplicarán las que existan sobre casos análogos; y no habiéndolas, se ocurrirá a los principios del derecho universal.

\section{$\underline{\text { Análisis }}$}

El artículo 18 del Código Civil ecuatoriano establece los mecanismos de interpretación de las normas, donde se plantea que el juez debe interpretar la norma con respecto al espíritu de la misma y considerar el principio de Favorabilidad.

También el artículo 3 de la Ley Orgánica de Garantías Jurisdiccionales y Control Constitucional menciona:

Las normas constitucionales se interpretarán en el sentido que más se ajuste a la Constitución en su integralidad, en caso de duda, se interpretará en el sentido que más favorezca a la plena vigencia de los derechos reconocidos en la Constitución y que mejor respete la voluntad del constituyente. Se tendrán en cuenta los siguientes métodos y reglas de interpretación jurídica constitucional y ordinaria para resolver las causas que se sometan a su conocimiento, sin perjuicio que en un caso se utilicen uno o varios de ellos:

1. Reglas de solución de antinomias: cuando existan contradicciones entre normas jurídicas, se aplicará la competente, la jerárquicamente superior, la especial, o la posterior.

2. Principio de proporcionalidad: cuando existan contradicciones entre principios o normas, y no sea posible resolverlas a través de las reglas de solución de antinomias, se aplicará el principio de proporcionalidad. Para tal efecto, se verificará que la medida en cuestión proteja un fin constitucionalmente válido, que sea idónea, 
necesaria para garantizarlo, y que exista un debido equilibrio entre la protección y la restricción constitucional.

3. Ponderación: se deberá establecer una relación de preferencia entre los principios y normas, condicionada a las circunstancias del caso concreto, para determinar la decisión adecuada. Cuanto mayor sea el grado de la no satisfacción o de afectación de un derecho o principio, tanto mayor tiene que ser la importancia de la satisfacción del otro.

4. Interpretación evolutiva o dinámica: las normas se entenderán a partir de las cambiantes situaciones que ellas regulan, con el objeto de no hacerlas inoperantes o ineficientes o de tornarlas contrarias a otras reglas o principios constitucionales.

5. Interpretación sistemática: las normas jurídicas deberán ser interpretadas a partir del contexto general del texto normativo, para lograr entre todas las disposiciones la debida coexistencia, correspondencia y armonía.

6. Interpretación teleológica: las normas jurídicas se entenderán a partir de los fines que persigue el texto normativo.

7. Interpretación literal: cuando el sentido de la norma es claro, se atenderá su tenor literal, sin perjuicio que, para lograr un resultado justo en el caso, se puedan utilizar otros métodos de interpretación.

8. Otros métodos de interpretación: la interpretación de las normas jurídicas, cuando fuere necesario, se realizará con atención a los principios generales del derecho y la equidad, así como los principios de unidad, concordancia práctica, eficacia integradora, fuerza normativa y adaptación.

\section{$\underline{\text { Análisis }}$}

El artículo 3 de la Ley Orgánica de Garantías Jurisdiccionales y Control Constitucional, establece los principios de interpretación de la ley, y la prioridad que se debe otorgar en cada caso que se presente (Torres, 2014). 


\section{REFERENCIAS BIBLIOGRÁFICAS}

Asamblea Constituyente. (2008). Constitución de la República del Ecuador. En A. Constituyente, Constitución de la República del Ecuador. Montecristi.

Asamblea Constituyente. (2008). Régimen de Transición (2008). En A. Constituyente, Constitución de la República del Ecuador. Montecristi.

Corte Constitucional. (2008). Sentencia Interpretativa: 002-08-SICC de los casos acumulados 005-08-IC y 009-08-IC, Corte Constitucional. Quito

Código Civil ecuatoriano (2005)

Facultad PUCP. (2015). Elaborar un informe legal. Obtenido de Facultad PUCP: http://facultad.pucp.edu.pe/derecho/wp-content/ uploads/2015/08/Formato-para-elaborar-el-Informe-Jur\%C3\%ADdico-de-una-sentencia1.pdf

García, T. (2013). El FODA: Una técnica para el análisis de problemas en el contexto de una planeación de organizaciones. Investigaciones del IIESCA, 84-98.

Ley Orgánica del Consejo de Participación Ciudadana y Control Social (2009)

Ley Orgánica Electoral, Código de la Democracia (2009)

Ley Orgánica de Garantías Jurisdiccionales y Control Constitucional (2009)

Torres, T. (2014). Factores que explican la relación principal-agente. Equidad Desarro, 137-163. 
Recibido: $31 / 08 / 2017$

Aprobado: 25/05/2018

Valeria Monserrath Sánchez Morales: Investigadora Jurídica Estudio Jurídico Cevallos \& Noboa

Correo electrónico: monse-2498@hotmail.com 